\title{
Nuestro derecho a escribir: Nelson Estupiñán Bass contra las necropolíticas de Estado en Los canarios pintaron el aire de amarillo 1
}

Ariadna N. Tenorio

Doctora en Ciencias Sociales por la Universidad de Colima

Universidad de Kansas, Kansas, Estados Unidos

$\frac{\text { https://orcid.org/0000-0001-7448-1431 }}{\text { ariadnatl@ku.edu }}$

\begin{abstract}
Resumen
La obra de Nelson Estupiñán Bass constituye un referente de la literatura afrolatinoamericana que transgrede el paradigma blanco-mestizo, al visibilizar la falsa igualdad a partir de la cual se constituyeron las naciones latinoamericanas. Partiendo de la noción de necropolítica desarrollada por Achille Mbembe, en este artículo se analizarán las estrategias narrativas de las que se vale Estupiñán, en la novela Los canarios pintaron el aire de amarillo (1993), para reivindicar las luchas emancipatorias de las comunidades indígenas y afro, al evidenciar las políticas de la muerte que ejerce el Estado sobre los cuerpos no deseados y mostrar cómo la alianza de estos cuerpos es la única forma de sobrevivir a la pérdida ocasionada por el despojo del que históricamente han sido objeto. Estupiñán reafirma, a través de su obra, el derecho que tenemos los afrodescendientes a hacer de la escritura no solo un medio de resistencia, sino también de emancipación, que nos permita disputar otros imaginarios posibles.
\end{abstract}

Palabras clave: Afrodescendendientes; Estupiñán Bass; literatura afrolatinoamericana; luchas emancipatorias; necropolítica.

\section{Our right to Write: Nelson Estupiñán Bass Hgainst the Necropolitics of the State in Los canarios pintaron el aire de amarillo}

\section{Hbstract}

The work of Nelson Estupiñán Bass constitutes a point of reference for Afro-Latin American literature that transgresses the white-mestizo paradigm by making visible the false equality on

1 Procedencia del artículo: Este artículo forma parte de la investigación doctoral sobre literatura afrolatinoamericana de la autora.

Esta obra está bajo una Licencia Creative Commons Atribución-NoComercial Compartirlgual 4.0 Internacional. Universidad del Valle, Cail, Colombia 
which the Latin American nations were constituted. Starting from the notion of Necropolitics developed by the Cameroonian philosopher Achille Mbembe, I analyze the narrative strategies that Estupiñán uses in the novel Los canarios pintaron el aire de Amarillo (1993), to vindicate the emancipatory struggles of Indigenous and Afro communities, by showing the politics of death exercised by the state on unwanted bodies and asserting how the alliance of these bodies is the only way to survive the loss caused by the dispossession to which they have historically been subjected. Estupiñán reaffirms, through his work, the right that We Afro-descendants have to make writing not only a means of resistance but also of emancipation that allows us to dispute other possible imaginaries.

Keywords: Afro-descent; Afro-Latin American literature; Emancipatory Struggles; Estupiñán Bass;

Necropolitics.

Recibido: 15 de agosto del 2020. Hprobado: 02 de octubre del 2020

Artículo de revisión https://doi.org/10.25100/poligramas.v0i51.10879

\section{¿Cómo citar este artículo en MLH? - How to quote this article in MLA?}

Tenorio, Ariadna N. "Nuestro derecho a escribir: Nelson Estupiñán Bass contra las necropolíticas de Estado en Los canarios pintaron el aire de amarillo" Poligramas 51 (2020): n. pag. Web. Fecha de acceso (día, mes en mayúscula y abreviado, y año).

\footnotetext{
2 / write what / like es la frase que da título a la colección de ensayos y discursos del activista y pensador sudafricano Steve Biko. Es también el título de la sección en la que Biko publicaba, bajo seudónimo, en el periódico de la Organización Estudiantil Sudafricana durante el periodo del apartheid. Su traducción literal al español sería: "yo escribo lo que quiero». Sin embargo, el uso de la expresión en su idioma original refiere más bien a: "yo escribo lo que me da la gana», en medio de la situación de censura y represión que terminó por costarle a Biko la libertad y, finalmente, la vida. "I write what I like» condensa el derecho que tenemos los negros a nombrarnos y a existir.
} 


\section{Introducción: ¿escribir o no sobre los cuerpos racializados?}

Hace poco en la videoconferencia "Literatura afrocentrada», organizada por los escritores afrolatinoamericanos Fabián Villegas, Yaissa Jiménez y Marleys Meléndez, se discutía si las expresiones narrativas afrodiaspóricas debían considerarse un género particular y si, en todo caso, era o no necesario que los autores afro abordaran, en su escritura, la experiencia racializada. Este no es, obviamente, un tema nuevo, como lo menciona Ngūgī wa Thiong'o en el congreso "Escritores Africanos de Expresión Inglesa», llevado a cabo en 1962, en Kampala, Uganda, donde se discutieron las características con las que debía cumplir un texto para ser considerado literatura negra: ¿tenía que hablar de África, debía versar sobre la experiencia africana o bastaba con que fuera escrito por un autor africano? (31-32). De forma similar, Latinoamérica había discutido el tema en el "Coloquio de la negritud y América Latina», llevado a cabo en 1947, en Senegal (Zapata 58-59). El mestizaje latinoamericano, sin embargo, complejizaba aun más la ya de por sí difícil empresa de definir, de manera más o menos unívoca, a la literatura negra, pues, como bien refiere Zapata Olivella, en 1974, muchos de los mulatos, zambos y mestizos latinoamericanos no habían asumido su negritud (62). Aunado a ello, habría que tener en cuenta que, independientemente de que el siglo $X X$ latinoamericano se viera influenciado, por un lado, por el negrismo europeo, caracterizado, en palabras de Quince Duncan, como un movimiento fluctuante entre el paternalismo y la estigmatización racista flagrante (Afrorealista 135), y, por otro lado, por la idealización de la estética negra de la negritud promovida por Léopold Senghor y Aimé Césaire (El Afrorealismo) ${ }^{3}$.

Es un hecho que algunos escritores afrolatinoamericanos se volcaron a la tarea de definir su literatura más allá de las etiquetas provenientes de movimientos literarios o sociales del exterior. Así, el afrocolombiano Manuel Zapata Olivella, reflexionando a partir de la influencia que la negritud había tenido en la literatura afrolatinoamericana, afirmaba, ya en 1988, que la de América Latina era una negritud descolonizadora capaz de "reivindicar la identidad contra las nuevas formas de colonización" (65). El afrohaitiano René Depestre, reflexionando, también, sobre el movimiento de la negritud, llegaba a la conclusión de que, sin importar la etiqueta que

\footnotetext{
3 Para un análisis extenso sobre el papel del mestizaje en la recepción del negrismo y la negritud en América Latina, véase Peter Wade (8-38) y Jerome Branche (483-504). Para entender cómo han mutado los conceptos del negrismo y la negritud entre los intelectuales latinoamericanos, véase Lesley Feracho (1-7) y María Elena Oliva $(47-72)$.
} 
se le pudiera dar, en América Latina había existido desde la colonia una cimarronearía cultural presente hasta nuestros días, que se caracterizaba por "hacer prosperar el sentido universal de la libertad y de la identidad humana" (214). Por su parte, el afrocostarricense Quince Duncan, alejándose de las concepciones impuestas por el negrismo y la negritud, acuña, en 1996, el término de afrorealismo para literatura negra latinoamericana. En su «Manifiesto Afrorealista», del 2006, Duncan refiere a esta literatura como aquella capaz de restituir a la comunidad afrodescendiente su propia voz, en un proceso de sanación y recreación de una conciencia fragmentada que llama a la diversidad y a la inclusión (Afrorealista... 141-142)

A partir de lo anterior, es posible observar que, independientemente de las posturas sobre cómo nombrar la literatura afro, el consenso apunta a considerarla una estrategia emancipadora, y al hecho de que, sin importar lo que se escriba, se escribe desde un cuerpo negro y que, por tanto, se hace desde una experiencia racializada. En este sentido, y a pesar de que la obra del afroecuatoriano Nelson Estupiñán Bass ha sido catalogada como negrista, tanto por Shirley Jackson (1986) como por Salvador Bueno (2003), y como afrorealista, por Quince Duncan (2006), la posición de Estupiñán era la de adscribir su obra tanto al negrismo como a la negritud, pues, aunque en su ensayo de 1981 "Aristas negras» reconoce la diferencia entre ambas corrientes, se decanta por una posición similar a la de Nicolás Guillén, en el sentido de que el negrismo latinoamericano "es una expresión de unidad histórica" (Guillén 296). Así, en sus «Aristas negras», Estupiñán reconoce que "los poetas negros y negristas convivientes con la libertad desde su nacimiento, han alzado desde sus primeros versos las banderas de la libertad y la protesta" (Aristas... 69), y afirma que "poetas negros y negristas confluyen con sus voces en la reivindicación de la libertad escamoteada o próxima” (Aristas... 67). Es decir, parece claro que, para Estupiñán, más allá de las etiquetas y las temáticas que se abordasen, la urgencia residía en la importancia de escribir desde el cuerpo negro en su contexto específico; por ello se entiende que, por un lado, pugnara por la universalización de la escritura afroecuatoriana (Desde un balcón 63) y, por otro, afirmara la necesidad de abordar los temas negros en la escritura de los autores afroecuatorianos (Estupiñán ctd. en Bolden 14-16).

A pesar de que críticos como Miranda Robles, Stanley Cyrus y Henry Richards han reconocido en la obra de Estupiñán una escritura combativa que, como señala Marvin Lewis en su «Nelson Estupiñán Bass: una introducción a sus escritos», se caracteriza por su compromiso con las comunidades marginadas (no solo la negra) y por su clara posición antimperialista 
(11), el hecho específico de que el autor se adscribiera a dos corrientes distintas (el negrismo y la negritud) y la oscilación constante de su obra entre la oralidad y la escritura, entre la reivindicación de la negritud y la exigencia al Estado ecuatoriano de considerar al negro forjador y ciudadano de la patria, han ocasionado que críticos como Michael Handelsman le reclamen a Estupiñán Bass escribir sobre la «Ciudad Real» desde la "Ciudad Letrada». En palabras del propio Handelsman: "La escritura como tal conlleva toda una historia de conquista y desplazamientos frente a la oralidad de los pueblos ágrafos e iletrados. Por lo tanto, escribir desde la Ciudad Letrada que, en muchos sentidos sigue perfilándose como uno de los centros del poder institucional, dificulta la verdadera aceptación de otras formas de expresión" (129).

En este sentido, para Handelsman, Estupiñán Bass refuncionaliza el discurso insurgente cimarrón amoldándolo "a los gustos de un público condicionado desde la colonialidad del poder" (116), un público que "en su mayoría no conoce a los afrodescendientes más allá de las marimbas" (128). Es decir, a Estupiñán se le reclama que como negro sepa hacer uso no solo de una tradición comunitaria (la oralidad), sino que sea capaz de articular ese mismo discurso a través de medios hegemónicos como la literatura. Como si Estupiñán no tuviera derecho de hacer suya la escritura, como si un negro no tuviera derecho a exigir para él y para otros la garantía de ser considerados completamente ciudadanos, como si su trabajo no siguiera (aun hoy, a 100 años de su nacimiento) horadando las fronteras de la "Ciudad Letrada», como si su escritura no hubiera reivindicado nuestra negritud más allá de las marimbas, como si su literatura no fuera un legado para la humanidad, pero sobre todo para nosotros los prietos.

La obra de Estupiñán es una declaración identitaria que, como menciona Mbembe al referirse a la conciencia negra, es una escritura que se encuentra "allí donde no se piensa que está" (Critique 28), donde el otro no lo espera; es el discurso insurgente cimarrón paseándose gozosamente y sin remordimiento por la "Ciudad Letrada». Como Steve Biko, Estupiñán escribe lo que le da la gana, lo que quiere; escribe siendo crítico de un país al que murió amando profundamente; escribe desde el cuerpo negro y sobre el cuerpo negro racializado, de una forma que para algunos puede resultar contradictoria, pues, a pesar de reafirmar la diferencia, Estupiñán comprende, al igual que Fanon (Sociología 18) y Mbembe (Critique 180), que la afirmación de la diferencia es apenas el principio de un proyecto más ambicioso e integrador y no su conclusión. 
En su discurso, Estupiñán señala estos dos puntos de una dialéctica que para un sujeto blanco se antoja contradictoria e incluso incomprensible. Esta dialéctica, que comienza con la tesis de reafirmar la identidad a partir de la diferencia y del cuerpo, para arribar a una síntesis unificadora y liberadora, parece inaprehensible para un sujeto blanco cuya socialización corporal ocurre en un sistema que creó la diferencia desde la "superioridad» de la blanquitud y de la opresión del diferente. La tesis liberadora de Estupiñán no se funda en el sujeto blanco, sino en todos aquellos sujetos históricamente oprimidos. Es claro, entonces, que su postura es escribir sobre los cuerpos racializados. De acuerdo con lo anterior, esta reflexión se ocupará del análisis de la novela Los canarios pintaron el aire de amarillo, en la que Estupiñán evidencia claramente las políticas de muerte que ejerce el Estado sobre los cuerpos racializados, un tipo de políticas violentas que pueden ser observadas a partir del concepto de necropolíticas del filósofo camerunés Achille Mbembe.

Para ello se explora, en primer lugar, la forma en la que el autor despliega, en su narración, el discurso hegemónico (blanco-criollo) y el discurso subalternizado (indígena y negro) ${ }^{4}$, mostrando cómo la «contradicción» del discurso subalternizado (esa misma contradicción que Handelsman le reclama a Estupiñán) surge precisamente del mandato hegemónico que impone como condición civilizatoria la renuncia al ser colectivo. A pesar de ello, Estupiñán elabora un discurso en el que, lejos de la renuncia, propone la construcción de un nosotros. En segundo lugar, se rastrea, en la novela, la forma en la que el Estado independiente refuncionaliza el entramado colonial que dio origen a la racialización de las poblaciones negras e indígenas. Finalmente, se muestra cómo estas violencias continúan colocando a las poblaciones racializadas por debajo de la línea de lo humano.

\section{Nos(otros)}

Los canarios pintaron el aire de amarillo explora el desencuentro entre negros e indígenas en una situación neocolonial, mediante el relato del despojo de tierras y el diezmo de la población indígena cayapa (cayanas en la novela), ocurrida hacia finales de los años setenta en Ecuador. Se trata, por consiguiente, de un hecho real ficcionalizado.

\footnotetext{
${ }^{4}$ El uso de las expresiones "discurso hegemónico», "discurso indígena» y "discurso negro» hace referencia, en este texto, al conjunto de ideas con las que Nelson Estupiñán Bass expresa, en la novela, el punto de vista criollo, indígena y negro, respectivamente.
} 
Estupiñán entrelaza en su narración el discurso hegemónico y el discurso subalternizado (el indígena y el negro), logrando mostrar no solo la falsa igualdad de las llamadas naciones mestizas latinoamericanas, sino, de paso, cuestionando qué tipo de progreso y conocimiento es válido y por qué. Así, la novela inicia con un aliento al más puro estilo antropológico del siglo XIX, esto es, una mirada supuestamente objetiva que clasifica la otredad partiendo de un prejuicio evolucionista y una idea de progreso occidentalocéntrico: "Los cayanas son trabajadores a medio tiempo, pues, por carecer de mayores ambiciones, laboran solo para cubrir sus más elementales necesidades" (Estupiñán, Los canarios 11). El que tal afirmación sea una de las primeras líneas de la novela no resulta menor, pues concuerda con lo afirmado por Mbembe en relación con que los procesos de racialización establecidos a partir de la violencia colonizadora responden a una lógica de acumulación; es decir, el sistema clasificatorio permitía (y sigue permitiendo) justificar quién es improductivo, quién es explotable y, por tanto, qué cuerpos no son deseables, pues no cumplen o dejan de cumplir con esa función de acumulación necesaria para el sistema (Critique, Necropolitics). En ese sentido, las líneas de Estupiñán se convierten en el preámbulo de la violencia que vendrá y que Mbembe denomina necropolíticas: la instrumentalización de la existencia humana y la destrucción material de los cuerpos; esto es, la capacidad del Estado para definir quién importa y quién no, qué vidas son desechables y cuáles no, quién muere y de qué forma muere (Necropolitics 79).

El discurso indígena gira en torno al poder autonómico, el derecho a organizarse socialmente y gobernarse, independientemente de las formas establecidas por el Estado. Así, por ejemplo, la educación se centra en la preservación de la tradición, el respeto a la comunidad y al territorio en el que se habita (Estupiñán, Los canarios 12). El discurso indígena disputa de forma constante el discurso hegemónico; en función de estas disputas quedan claras las negociaciones o concesiones que ha tenido que hacer la comunidad cayana para asegurar no solo su autonomía sino su supervivencia: como aceptar la alfabetización de su población o conceder la entrada de turistas a su territorio.

Si bien estas concesiones se pueden antojar simples, Estupiñán intenta problematizarlas a tal punto que es posible observar el conflicto que "oscila del aislamiento a la apropiación y de la resistencia a la asimilación" (Miranda 182-183). La propia comunidad quedará dividida entre aquellos que luchan por conservar su forma de vida y quienes buscan «civilizarse». Por lo tanto, el discurso indígena parece ser contradictorio de una forma muy similar a la que a Handelsman 
le parece contradictoria la totalidad del discurso de Estupiñán. Una «contradicción» que nace del intento de mantener un equilibrio entre dos fuerzas consideradas por el discurso hegemónico opuestas entre sí: habitar el mundo exterior sin dejar de ser cayana (o negro esmeraldeño, en el caso de Estupiñán). Para el sujeto racializado, la búsqueda de este equilibrio tiene por objeto guardar algo que sea digno de considerarse vida y no renunciar a lo que se es. Pero, para el discurso hegemónico, esta búsqueda resulta contradictoria, pues unirse al proyecto civilizatorio entraña de facto dejar de ser. Esta renuncia, como lo señala Mbembe, implica para el sujeto racializado abandonar el sentido de comunalidad, toda vez que la racialización es en sí misma la negación de lo común (Critique 54). Así, la integración del sujeto racializado al proyecto civilizatorio no lo desracializa, sino que lo convierte en una suerte de ciudadano simbólico que difícilmente será considerado igual a aquel que, en principio, estableció la diferencia. En esta renuncia, el sujeto racializado ha perdido la comunidad y ha tenido que aceptar convertirse en un «no ser».

La tensión entre ambos discursos llega a tal punto que se buscan romper la comunalidad a través no de los sujetos que persiguen la promesa civilizatoria, sino de aquellos que, amando profundamente el sentido de comunalidad cayana, habían logrado empujar lentamente, y no sin tropiezos, los cambios antes mencionados: el "General» Veintemilla, Manuela León y Susana Peralta, apodados «los tres diablos». Estupiñán plantea cómo, tras la inauguración de la nueva Punta del Viento (la ciudad cayana había tenido que ser reconstruida tras un incendio) y ante la noticia de la enorme afluencia de turistas, dos empresarios se acercaron al anciano Piguala (gobernador cayana) para proponerle construir en su territorio estancias para los turistas y centros nocturnos. Ante la negativa del gobernador, habrían acudido a "los tres diablos» para plantearles la idea y solicitar que Susana Peralta (joven cayana) trabajara en un centro nocturno de la ciudad de Cascabel, en donde no solo tendría sueldo, comida y hospedaje, sino que también le sería proporcionada "ropa civilizada" (Estupiñán, Los canarios 34-36). Estas fracturas, como veremos más adelante, no son gratuitas y constituyen una forma muy clara de violencia en contra de la comunidad cayana.

Estupiñán resuelve, de forma extrema, mediante el personaje de Susana Peralta, el falso dilema que se le plantea al sujeto racializado al unirse al proyecto civilizatorio. Susana viaja (a escondidas del anciano Piguala) a trabajar, con los dos empresarios, a la ciudad de Cascabel. Después de un breve periodo, la joven cayana se da cuenta de que está ahí para ser prostituida. 
¿Qué forma más clara de señalar la objetivación del sujeto racializado? ¿Qué forma más clara de exponer a qué sujeto puede explotarse? Susana sabe que lo ha perdido todo, no ha sido en realidad "civilizada», no fue ella quien eligió el oficio, y, aun si abandona el supuesto trabajo que tiene y busca en la ciudad de Cascabel otra forma de ganarse la vida, no está segura de tener el derecho de poder ser al mismo tiempo cayana y este nuevo sujeto que ahora es.

El discurso negro que Estupiñán plantea en el texto busca, de forma similar al indígena, comunalidad y autonomía. Se trata, sin embargo, de un discurso mucho más negociador que el indígena. Esto se debe, como lo señala Miranda Robles, a que el negro ya había tenido que buscar comunidad entre la heterogeneidad étnica extirpada de África para ser esclavizado en América (179-180). Este discurso negociador no es necesariamente ni pacífico ni impulsivo, es, más bien, un discurso que ha aprendido a transar la violencia con la violencia. Una violencia que es posible leer en términos fanonianos, pues busca exponer sus dimensiones psicológicas y políticas más profundas al mostrar cómo, a pesar de la permanencia de la herida colonial, el discurso constituye una invitación abierta a la configuración de un nosotros. Así, cuando Estupiñán plantea en su texto que los cameruneses habían ofrecido sin costo alguno, al pueblo cayana, madera para la reconstrucción de la ciudad tras el incendio (Los canarios 123), o cuando refiere que, a pesar de las negativas cayanas, los cameruneses seguían recibiéndolos en su territorio, como si se tratase de viejos amigo (Los canarios 50), muestra, en el cuidado del otro, la posibilidad de la reciprocidad. Una práctica que Mbembe define como "el encuentro auténtico con otros" (Políticas 22). La posibilidad de que, pese al odio ancestral que, por mandato, los cayanas profesaran a los cameruneses, pudiesen, en algún momento, reconocerse en ellos. Este "encuentro auténtico con otros" queda plasmado en la narración de Estupiñán cuando el anciano Piguala afirma: "ya no somos enemigos, ahora usted [cameruneses] y nosotros [cayanas] somos amigos, más que eso, somos hermanos" (Los canarios 127).

La contradicción es que el discurso negro plasmado por el autor resulta conciliador y, a la vez, violento. La misma contradicción, que como ya hemos dicho, le reclama Handelsman a Estupiñán, ha de entenderse como la contradicción generada por un sistema (neocolonial, en el caso de la narración de Estupiñán) que impone, sobre los cuerpos racializados, la indeterminación de la vida. La violencia discursiva se ejerce, como veremos más adelante, contra la violencia de dicho sistema y comienza por el reconocimiento mutuo de aquellos que han sido colocados en la categoría de «lo otro »; se trata de una violencia que no implica únicamente la 
utilización de "escopetas, machetes, perros y garrotes" (Los canarios 123), sino que inicia por la posibilidad de desmantelar el estatus quo, un proceso en el que la otredad se convierte en una comunidad extendida que derriba las fronteras interiores impuestas por el Estado.

\section{La refuncionalización de la violencia colonizadora}

En la novela, Estupiñán recurre al relato fundacional de la ciudad de Punta del Viento en la época colonial (la ciudad cayana), para dejar claro la génesis de la violencia ejercida sobre esta población:

Los indios cayanas, asentados al pie del nevado Imbaya, entre los Andes ecuatorianos, volvieron cenizas sus viviendas, y, guiados por sus exploradores, iniciaron el descenso a la costa.

Los españoles del recinto, que ya habían empadronado a los adultos para su traslado a un obraje, huyeron del fuego (Estupiñán, Los canarios 9).

Achille Mbembe define la ocupación colonial, en primer lugar, como una reorganización del espacio geográfico que inscribe la forma de control sobre los sujetos categorizados a través del proceso de racialización (Necropolitics 78). De forma similar, Daniel Nemser argumenta que, para el caso del continente americano, las autoridades coloniales se sirvieron durante siglos de la organización espacial de los cuerpos. Esta organización de cuerpos habría estado íntimamente ligada a las políticas raciales (2-5). Para ambos autores, son los procesos de racialización los que hacen posible la extracción y la acumulación, mostrando así que la subjetividad racializada es más un resultado de las prácticas materiales del poder que un atributo particular marcado por la diferencia.

El empadronamiento y el obraje constituyen, en la novela, los primeros signos de la reorganización espacial y categorización racial colonial que habrían de tener consecuencias materiales en la subjetivación de los cayanas. Siguiendo el pensamiento de Mbembe, estos implican la puesta en marcha del necropoder imponiendo la fragmentación territorial que impide la libre movilidad del sujeto racializado (Necropolitics 80). El padrón, en ese sentido, se convierte en el registro del paso del sujeto al objeto, el registro del paso de la libertad a la propiedad del dueño del obraje. El documento en sí es garante del estado de excepción en el 
que funciona el espacio físico delimitado para tales labores. La violencia que ocurre en su interior ocurre siempre al servicio de la acumulación de bienes. El padrón es documento testigo de que los cayanas, quienes después de haber quemado sus viviendas habían huido de los españoles y de su inminente traslado al obraje, se han convertido en una suerte de propiedad en fuga. Fugitivos que, aun en calidad de huida, quedan sujetos, según Mbembe, a una matriz de reglas diseñadas exclusivamente para aquellos cuerpos que, a pesar de ser humanos, son considerados prescindibles, no deseables (Necropolitics 96).

Nada de lo que incluye este autor afroecuatoriano en la narración se reduce a un recurso meramente estético. Estupiñán va de ida y vuelta al pasado para hacer presente el entramado colonial que a través de los años se ha refuncionalizado en el ahora Estado independiente, y lo hace poniendo especial atención en la relación (o la ausencia de esta) entre cayanas y cimarrones. La narración deja claro que los cayanas "mantienen un odio ancestral para el hombre negro" (Estupiñán, Los canarios 12), un odio que se remonta a la colonia y que surge a partir de la violencia que los cimarrones ejercieron sobre los indígenas. Es por eso que "jamás un cayana desposó a una mujer negra [y], tampoco un cayana fue enterrado donde duermen los despojos de un descendiente africano" (12-13). Una de las violencias ejercidas por la necropolítica, nos dice Mbembe, consiste justamente en la subdivisión de aquellos cuerpos que han sido ya clasificados como indeseables y, por tanto, explotables. Este tipo de políticas promueve la distancia social y la creación de fronteras físicas y culturales entre los subgrupos creados (Necropolitics 74). Así, independientemente de lo planteado por Estupiñán en la narración, no es secreto que los españoles favorecían el distanciamiento entre negros e indígenas no solamente mediante las medidas clasificatorias del sistema de castas, sino también a partir de las funciones que les eran asignadas a unos y a otros. En muchos de los obrajes, por ejemplo, el indígena quedaba bajo vigilancia y supervisión del negro, convirtiéndolo así en "esclavo del esclavo" (Tardieu 527). Estupiñán mismo había ya señalado la permanencia de esta estrategia de origen colonial en su novela Cuando los guayacanes florecían (1954), al narrar cómo, cuando los negros de Esmeralda se unen a la Revolución Conchista (1913-1916), el gobierno envía un batallón conformado por indígenas a combatirlos. Si el fomento de esta división estaba presente a principios del siglo XX, el autor nos muestra su permanencia hacia finales de ese mismo siglo. 
Estupiñán no es ingenuo, por experiencia propia sabe que ninguno de estos dos pueblos carece de agencia, de modo que no recurre al victimismo al narrar la violencia. No pretende tampoco ser esencialista, sabe que no existe cosa tal como características inherentes a un grupo humano particular; a través de sus letras, desmonta los estereotipos del indígena agachado y del negro violento, mostrando las circunstancias históricas que, en todo caso, empujaron esas clasificaciones. No por ello deja de reconocer cómo la fuerza de esos estereotipos se constituye en una estrategia divisoria que termina por tener efecto en lo que unos piensan de los otros: "Durante algún tiempo los cameruneses se devanaron los sesos tratando de saber las causas del desprecio y del odio de los cayanas. No encontrando razón verdadera alguna, llegaron a la conclusión de que esos 'infelices indios' eran 'unos pendejos'” (Estupiñán, Los canarios 27).

De acuerdo con Mbembe, la esencialización de las características, ya sean físicas o culturales, de un grupo particular de sujetos es constituyente de las diversas formas de asignación racial que terminan por inscribirse en el cuerpo del sujeto racializado. Lo que a la postre resulta ser extremadamente conveniente, pues, dado que la racialización no depende únicamente de un efecto óptico, el imaginario creado por la imposición de estos esencialismos se convierte en una forma de asentar y afirmar el poder (Critique 28-37). Con fundamento en estos esencialismos se puede, por un lado, estafar al indígena, dado que, además de agachado, es ignorante. Así, el extranjero que en algún momento había engañado al cayana Julio Grosella, al pagar el costo de las canoas que vendía con recortes de papel periódico, se toma el atrevimiento de viajar hasta Punta del Viento para "comprar» más canoas. Ante la sorpresa del accidentado recibimiento, ofrece pagar el valor de los billetes; la respuesta del anciano Piguala es enfática: "nuestra justicia no es como la de ustedes" (Estupiñán, Los canarios 45). Por otro lado, puede engañarse al negro porque es tonto, pero el engaño debe hacerse por medio de la adulación y con mucho cuidado, pues es vanidoso, aunque violento. Así, cuando el sujeto que se hacía pasar como profeta (un hombre que recolectaba dinero para la construcción de un supuesto templo) se dirige al negro Timoteo diciéndole que como los cameruneses son los más inteligentes de la región son los que más dinero tendrían que dar: "El jefe negro le recalcó la pobreza en la que se debatía Camerún" (68). Quizás Estupiñán se inclina por romper con estos estereotipos mediante una resolución narrativa que puede parecer más bien simple, porque en 
el fondo, como refiere Mbembe, esta lógica esencialista es una simpleza que "supone un fuerte grado de bajeza y estupidez" (Critique 36).

A lo largo de la novela es posible seguir las huellas de la refuncionalización de la violencia colonial, cuyo fin sigue siendo decidir quién vive y quién muere. Todas estas violencias se potencializan tras la inauguración de la nueva Punta del Viento, cuando los extraños han sido testigos de la riqueza natural y cultural del territorio cayana. Mencionamos ya el caso de los dos empresarios de ciudad Cascabel, quienes, además de la propuesta que le hicieron a Piguala, al "General» Veintemilla y a Susana Peralta, se dedicaron a tomar fotos y medidas del territorio cayana. A partir de ese momento, la comunidad parece tener únicamente dos opciones: convertirse en mano de obra al servicio de quien pretende explotar su territorio o intentar sobrevivir. Esta violencia no se ejerce únicamente en contra del pueblo cayana, la comunidad negra del poblado Camerún corre con la misma suerte, y el gobierno estatal aprovecha el desencuentro histórico de estas dos poblaciones para poner en venta el territorio.

\section{Por debajo de la línea de lo humano}

El día en que se inaugura Punta del Viento, la comitiva del gobierno estatal instala una bandera ecuatoriana en la casa principal de la ciudad cayana. Este acto es en sí una ocupación neocolonial, una territorialización del espacio geográfico habitado por los cayanas, la imposición de nuevas fronteras físicas y simbólicas que dejan de ser una simple línea de demarcación, para convertirse en el nombre que se usa para describir la violencia organizada que sustenta el funcionamiento del Estado (Mbembe, Necropolitics 99). La bandera funciona en la narración como la actualización del padrón colonial, dejando claro que los cayanas ni son autónomos ni son propietarios del territorio en el que habitan. Simbólicamente, se han convertido otra vez en propiedad, mercancía en fuga, una categoría que les recuerda que hace ya siglos que han sido colocados por debajo de la línea de lo humano. Los cayanas, quienes hasta entonces creían haber sido libres, se descubren de pronto bajo lo que Mbembe denomina "la lógica del cercado", y que tiene por objeto fijar con precisión los límites dentro de los cuales pueden circular determinados sujetos, delimitando, por tanto, los espacios que les son permitidos ocupar (Critique 35). El cercado y la frontera convierten al territorio cayana en un espacio desconectado de la idea misma de humanidad, no porque los cayanas no se consideren a sí mismos humanos, sino porque nuevamente son despojados de humanidad. 
En la narración, muy lejos de la metáfora, los cayanas empiezan a ser cercados por las estacas y las púas de los particulares a los que el gobierno estatal les ha cedido o vendido el territorio cayana. Estupiñán describe la lucha silenciosa y clandestina entre indígenas y extraños, que consistía en mover el cerco con el fin de evitar la constricción del pueblo cayana. Esta lucha es a la vez material y simbólica, pues no solo intenta defender la propiedad de un espacio físico, sino también la propiedad de un espacio intangible, pero de igual importancia: la comunalidad. Como si se tratase de ganado, los cayanas son contenidos en una geografía cada vez más pequeña, los huertos de los que obtenían gran parte de su alimentación quedaron del otro lado del cerco, los bosques que en algún momento habían sido considerados territorio sagrado han sido desmontados para dar lugar a viviendas de vacacionistas, los ríos en los que pescaban y se bañaban son ahora el vertedero residual de los complejos turísticos. Al igual que al ganado en fuga, a los cayanas se les dispara cuando intentan cruzar o comprometer el cerco. A diferencia del ganado, la materialidad de los cuerpos cayanas no es considerada valiosa; ahora no son ni siquiera objeto. Las enfermedades que han llegado (la lepra, la malaria y la oncocercosis), y se han agravado como consecuencia de la contaminación de su entorno, de la falta de alimentación y del bloqueo económico promovido por las autoridades estatales, han convertido a los cayanas en deshechos vivientes. Su ciudad es ahora una muy parecida a la que Fanon describe en Los condenados de la tierra:

La ciudad del colonizado, o al menos la ciudad indígena, la ciudad negra, la «medina» o barrio árabe, la reserva, es un lugar de mala fama, poblado por hombres de mala fama, allí se nace en cualquier parte, de cualquier manera. Se muere en cualquier parte, de cualquier cosa. Es un mundo sin intervalos, los hombres están unos sobre otros, las casuchas unas sobre otras. La ciudad del colonizado es una ciudad hambrienta, hambrienta de pan, de carne, de zapatos, de carbón, de luz. La ciudad del colonizado es una ciudad doblegada, una ciudad a rodillas, una ciudad revolcada en el fango (37-39).

Los cayanas son, en este punto de la narración, el producto de una de las formas más perversas de terror implementadas por las necropolíticas; han sido convertidos en un signo particular de existencia social; se trata de un muerto en vida en espera de la sentencia definitiva de muerte. En este estadio de muerto en vida, señala Mbembe, el sujeto vive bajo una inevitable alteración de la percepción de la temporalidad (Necropolitics 75). La inflicción continuada de 
violencia sobre el cuerpo epidermiza una sensación de suplicio eterno, mientras que la temporalidad de todo lo que ocurre fuera del cerco se acorta. Es posible observar, en el relato de Estupiñán, estas dos temporalidades. Por un lado, el autor extiende la narración de la ceguera que aqueja a la población (la oncocercosis), detalla que el padecimiento ha comenzado afectando únicamente a los más viejos, describe la llegada de una primera comisión de médicos: "los facultativos empadronaron a los enfermos, registraron en fichas los exámenes [...] señalaron como causa de la dolencia los mosquitos, sin llegar a precisar el tipo inoculador" (Los canarios 57-58). Para el momento de la llegada de la segunda comisión de médicos, la ceguera afecta también a los adultos, pues nuevamente "se examinaron las aguas estancadas y las corrientes, pero no se señalaron las causas de la epidemia" (61). Mientras la ceguera avanza, los encargados de la sanidad pública se debaten en un interminable "litigio ortográfico sobre si jején se escribía correctamente con g o con j” (72). Los médicos de la tercera delegación vacacionaron un mes en Punta del Viento, "concluyeron su informe que abarcó 480 páginas", pero que no explicaba la causa ni proponía una cura (74). La cuarta delegación de médicos enviada para atender la ceguera de la población cayana resultó ser un grupo de contrabandistas (84). Al arribo de la quinta comisión, esta vez compuesta por estudiantes de medicina, la ceguera comenzaba a extenderse entre los jóvenes. Los estudiantes elaboraron un diagnóstico que fue ignorado por las autoridades de sanidad pública (97).

En contraposición a lo anterior, el autor hace uso de una economía narrativa vertiginosa (aunque no menos cruda) para ocuparse de los hechos concretos que refieren a la invasión del territorio. El cayana Manuel Canalete fue devorado por los canes de uno de los concesionarios al intentar cruzar el cercado (92), Luciano Corvina y Bonifacio Gualanga fueron asesinados a tiros de escopeta cuando intentaban alterar los límites del cercado para recuperar su territorio (98): "más extraños invadieron los antiguos dominios cayanas. Construyeron casas, instalaron almacenes, sembraron pastizales, abrieron caminos" (111); "los cayanas veían cómo árboles, considerados intocables eran abatidos por motosierras y hachas y seccionados, prestamente embarcados con destino a lugares que ellos desconocían" (113).

Lo anterior (la diferencia entre el primer y segundo discurso) provoca, en efecto, la sensación de que el martirio físico de los cayanas ha sido un viacrucis interminable, mientas que la pérdida del territorio ocurre en, prácticamente, un abrir y cerrar de ojos. Ambos acontecimientos, sin embargo, ocurren a lo largo de un plazo de aproximadamente ocho meses, 
y el efecto material que estos tienen se concentra en una misma subjetividad: la cayana. La constricción del territorio y de la humanidad cayana borra, dentro del espacio delimitado por el cerco, el delicado límite entre la vida y la muerte. Como lo refiere Paul Gilroy, dentro del cerco el suicidio, la rebelión, la huida y el duelo silencioso se convierten en patrones extremos de comunicación, ramificaciones antidiscursivas (pues parecen contradictorias). El suicidio, bajo estas circunstancias (las del cerco), se constituye en agencia, pues la extinción de la vida propia se convierte en el único procedimiento sobre el cual el sujeto tiene poder. El cuerpo es, en ese momento, el espacio físico en el que operan al mismo tiempo la negación y la libertad (Gilroy ctd. en Mbembe, Necropolitics 75-93). Bajo esta lógica, no es de extrañar que la tradición cayana del suicidio celebratorio, cuando el sujeto sentía que había culminado su misión en la vida, se tornara, tras las invasiones, en la estrategia para recuperar en otra dimensión ese otro territorio intangible pero habitable: el de la comunalidad: "Luis Tamayo y Edelina Albacora [... ] no tuvieron hijos ni hermanos. Ahora estaban en la desvencijada banca, como habían caminado, pegado uno al otro, hechos una sola mano y una sola muerte" (Estupiñán, Los canarios 102). El suicidio y el duelo silente de la comunidad cayana no pasa desapercibido, es escuchado por otra comunidad que, al igual que la cayana, hace siglos que ha sido colocada bajo la línea de lo humano, una comunidad que entiende la aparente contradicción de las ramificaciones extralingüísticas. Los negros de Camerún, que a lo largo de esos mismos ocho meses han defendido su territorio a base de armas, acuden a Punta del Viento a defender también el territorio cayana.

Al final, ante la negativa de entregar de forma pacífica lo poco que quedaba de las tierras cayanas, los tractores de los concesionaros destruyen el pueblo. Veintemilla y Manuela son asesinados, los líderes negros que habían acudido a defender la ciudad cayana son "desaparecidos» y Susana es violada por el "ejército» pagado por los empresarios. Un nuevo incendio, esta vez provocado por las autoridades estatales, obliga a los pocos sobrevivientes cayanas a abandonar la ciudad. La novela cierra con una canoa río abajo y con los canarios (animal sagrado para los cayanas) sobrevolando el cielo y pintando el aire de amarillo. El "auténtico encuentro con otros", ese que Mbembe y Fanon definen como la emergencia de reciprocidad del cuidado del otro, y que ocurre entre aquellos seres que no comparten lazos originarios y han sido privados de humanidad (Necropolitics 5-7), abre la posibilidad de otros imaginarios, un futuro compuesto por nos(otros), "una llamada a la diversidad, a la inclusión, a 
la dignidad [...] un sitio y un tiempo para todas las expresiones de humanidad" (Duncan, Afrorealista 142).

\section{Reivindicando la lucha: nuestro derecho a escribir}

Estupiñán escribe, porque su escritura, junto con la de tantos otros autores afrodescendientes, constituye la fundación de un archivo necesario para restituirnos a la historia. Su escritura es en sí misma lucha y resistencia, pues la literatura es también espacio público, uno que durante mucho tiempo nos estuvo vetado. Estupiñán toma ese espacio, y, con sus letras, lo tomamos también nosotros y nos hacemos visibles, tornándonos un murmullo ensordecedor de marimbas, y rompemos el silencio, ese silencio que aun ahora insiste en colocarnos por debajo de la línea de lo humano. Estupiñán escribe y con ello rehabilita nuestra memoria y cada trozo de esa memoria transforma la "Ciudad Letrada», y entonces la hacemos nuestra, la bautizamos cimarrona, le rompemos los cercos, la dejamos libre y nos volvemos testigos de cómo se hace una con nuestra "Ciudad Real».

Estupiñán escribe, y, con sus letras, nos desnudamos de esencialismos, y dejamos de ser saltapatrás, lobos, gíbaros, no te entiendo, zambaigos o tente en el aire para simplemente ser y ser junto con otros. Estupiñán, como Biko, escribe lo que le da la gana, y escribimos también nosotros, porque cada escritura es una pequeña revuelta que pone en marcha la insurrección epistemológica con la que disputamos otros imaginarios posibles. Estupiñán escribe, porque con su escritura muestra que es posible buscar la igualdad a partir de la diferencia. Escribe desde la experiencia racializada y sobre la experiencia racializada, develando al racismo neocolonial como una herramienta estatal de la distribución inequitativa de la muerte. Con su escritura, Estupiñán urge al Estado a repensarse más allá de su poder soberano sobre la vida, toda vez que un Estado verdaderamente antirracista no es aquel que se limita al reconocimiento celebratorio de la multiculturalidad, sino aquel que garantiza la distribución equitativa de la vida y renuncia así a la administración de la muerte. 


\section{Referencias}

Biko, Steve. I write what / like: Selected writings. Chicago: University of Chicago Press, 2015. Impreso.

Branche, Jerome. "Negrismo: Hibridez cultural, autoridad y la cuestión de la nación". Revista Iberoamericana. Jul. - Dic. 1999: 483-504. Impreso.

Bolden, Millicent A. "Conversación entre Nelson Estupiñán Bass y Millicent A. Bolden". AfroHispanic Review. Sept. 1989: 14-16. Impreso.

Bueno, Salvador. Cuentos negristas. Caracas: Fundación Biblioteca Ayacucho, 2003. Impreso.

Cyrus, Stanley A. "Rage and Hope in the Works of Nelson Estupiñán Bass". Afro-Hispanic Review. Sept. 1983: 13-18. Impreso.

Depestre, René. Buenos días y adiós a la negritud. La Habana: Casa de las Américas, 1985. Impreso.

Duncan, Quince. "Afrorealista Manifesto". Hispanic Journal. Primavera. 2006: 135-143. Impreso.

Duncan, Quince. "El Afrorealismo. Una dimensión nueva de la literatura latinoamericana". Revista Virtual ISTMO. Julio. 2005: s. p. Digital.

Estupiñán Bass, Nelson. "Aristas negras". Cultura. May. - Agos. 1981: 51-80. Impreso.

Duncan, Quince. Cuando los guayacanes florecían. Quito: El Conejo, 1983. Impreso.

Duncan, Quince. Desde un balcón volado. Quito: Banco Central de Ecuador, 1992. Impreso.

Duncan, Quince. Los canarios pintaron el aire de amarillo. Ibarra: Editorial Universitaria, Universidad Técnica del Norte, 1993. Impreso.

Fanon, Frantz. Los condenados de la tierra. Tafalla: Txalaparta, 1999. Impreso.

Fanon, Frantz. Sociología de una revolución. México: Ediciones Era, 1976. Impreso.

Feracho, Lesley. "The Legacy of Negrismo/Negritud: Inter-American Dialogues". The Langston Hughes Review. Otoño - Primavera. 1999: 1-7. Impreso.

Guillén, Nicolás. Prosa de prisa. La Habana: Letras Cubanas, 1987. Impreso.

Handelsman, Michael. "Nelson Estupiñán Bass: en contexto". Guaraguao. Invierno. 2011: 110132. Digital.

Jackson, Shirley M. La novela negrista en Hispanoamérica. Barcelona: Pliegos, 1986. Impreso. 
Lewis, Marvin. Nelson Estupiñán Bass: una introducción a sus escritos. Quito: Casa de la Cultura Ecuatoriana Benjamín Carrión, 2017. Impreso.

Mbembe, Achille. Critique of black reason. Durham: Duke University Press, 2017. Impreso.

Mbembe, Achille. Necropolitics. Durham: Duke University Press, 2019. Impreso.

Mbembe, Achille. Políticas de la enemistad. Barcelona: NED Ediciones, 2018. Impreso.

Miranda Robles, Franklin. "Mirada afrodescendiente de la heterogeneidad indígena en 'Los canarios pintaron el aire de amarillo' de Nelson Estupiñán". Revista de crítica literaria latinoamericana. Ene. - Jun. 2007: 179-203. Impreso.

Nemser, Daniel. Infrastructures of race: concentration and biopolitics in colonial Mexico. Austin: University of Texas Press, 2017. Impreso.

Ngūgī, wa Thiong'o. Descolonizar la mente: la política lingüística de la literatura africana. Barcelona: Debolsillo, 2015. Impreso.

Oliva, María Elena Oliva. "Más acá de la negritud: negrismo y negredumbre como categorías de reconocimiento en la primera mitad del siglo XX latinoamericano". Revista CS. Ene. - Abr. 2020: 47-72. Digital. 10 agosto 2020.

Richards, Henry J. "Nelson Estupiñán Bass and the Historico-political Novel: From Theory to Praxis". Afro-Hispanic Review. Primavera - Otoño. 1983: 5-12. Impreso.

Tardieu, Jean Pierre. "Negros e indios en el obraje de San IIdefonso. Real Audiencia de Quito. 1665-1666". Revista de Indias. n. d. 2012: 527-550. Digital.

Villegas, Fabián, Yaissa Jiménez y Marleys Meléndez. "Literatura afrocentrada”. Contranarrativas. Web. 06 ago. 2020,

Wade, Peter y Teresa Bailach. "La política cultural de la negritud en Latinoamérica y el Caribe". Guaraguao. Verano. 2005: 8-38. Digital.

Zapata Olivella, Manuel. "Negritud, Indianidad y Mestizaje en Latino América". Présence Africaine. Ene. - Mar. 1987: 165. Impreso. 